\title{
The worm's turn to claim Internet fame
}

Paris

Caenorhabditis elegans, the favourite worm of developmental biology, now has its own Internet portal site. Wormbase, which can be found at http://www.wormbase.org, aims to bring together all available information on the millimetre-long soil nematode's genetics and biology.

Consisting of just 959 cells, the fates of which have been meticulously catalogued, the roundworm $C$. elegans is the leading model organism in developmental biology. Last year, it became the first complex organism to have its genome sequenced. Wormbase aims to integrate these data, and make them accessible to any biologist - not just those with expert knowledge of C. elegans.

"We want to make the database fun and easy to use, so that you don't have to be a roundworm insider to use it," says Paul Sternberg of the California Institute of Technology in Pasadena. Sternberg is leading the project, together with Lincoln Stein of the Cold Spring Harbor Laboratory on Long Island, New York, and Jean Thierry-Mieg of the Centre de Recherches de Biochimie Macromoléculaire in Montpellier.

John Spieth of the Washington University School of Medicine in St Louis and Richard Durbin from the Sanger Centre near Cambridge in England, representing the two

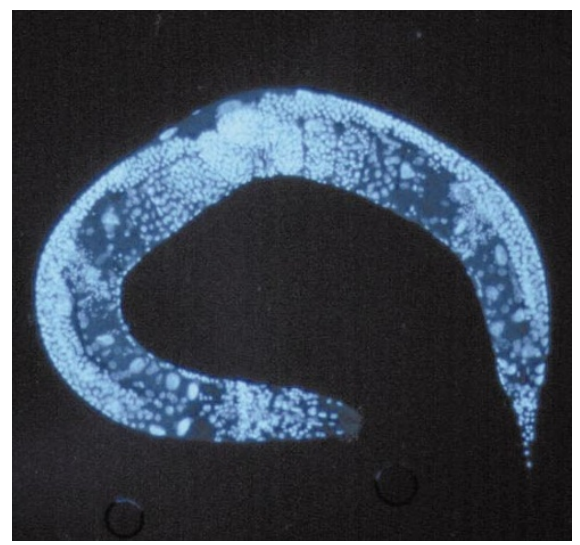

Browse a roundworm: visit www.wormbase.org

centres that sequenced the worm's genome, are also on board.

Until now, admits Sternberg, biologists outside the 1500-strong roundworm community may have found its obscure nomenclature off-putting. Few, for example, would have any idea that a cell called AB.alaaappr is the parent cell of AVDR, an important interneuron in the worm's ventral cord.

Wormbase users will require no such insider knowledge. "You will be able to come into Wormbase from a paper, a cell or a gene, or even a process," says Sternberg. For instance, the site will eventually allow users to zoom in on photographs of the worm and see what cells such as AB.alaaappr look like, what they do, and which cells they are sitting next to. It will also document where and when each of the 19,000 genes in the worm's 97million-base-pair genome is expressed.

"What is special about C. elegans is that we can see which genes are being expressed in which cell," says Sternberg, "and that we know what each of the cells does, and how they relate to each other." Ultimately, all the information should be available for a series of stages in the worm's development.

Wormbase is an example of a 'vertical' database that integrates many types of information about a single organism. Its model is Flybase, which serves researchers working on the fruitfly Drosophila. Sternberg believes that having the worm genome sequence early on was in some ways a disadvantage, as the focus on sequencing led to neglect of collating the literature on the worm's wider biology. The Drosophila community had to wait until earlier this month to get its genome, and wisely spent the waiting time in building up the Flybase portal, says Sternberg.

Another challenge for Wormbase will be interfacing its vertical information with the larger 'horizontal' databases, such as the GenBank sequence database, which span many species.

Declan Butler

\section{Radical changes urged for Spanish universities}

\section{Barcelona}

In an attempt to bring the structure and operating procedures of Spanish universities in line with those of other advanced nations, major reforms aimed at increasing the quality of scientific research and education at such institutions have been proposed in a report released in Madrid last week.

Entitled 'University 2000', the report has been drawn up by Josep Bricall, former president of the Council of European Rectors, at the request of the Council of Rectors of the Spanish Universities (CRUE).

Saturnino de la Plaza, CRUE's president, describes the proposals in the report as "unprecedented". In particular, the report recommends a complete revision of selection procedures for tenured university staff. It admits that this results from criticism of current recruitment procedures reflected in the large number of recent lawsuits which usually "base their claim on allegations of favouritism" (see Nature 400, 203, 401 \& 419; 1999).

The report points out that, when the current higher-education law that confers increased independence on universities came into force in 1983, it was initially thought that the high level of complaints over unfairness in the new recruitment system adopted at the time would be transitory. But even after 17 years, there are still a worryingly high number of legal challenges to selection procedures.

The new report now proposes that, once a post for an associate or full professor has been advertised, a panel of experts with no link to the university should make a judgement on the quality of the professional activities of the applicants, including their research, teaching and other activities.

The committee would list the candidates individually according to the results of this evaluation. A second panel, drawn from individuals at the institution advertising the post - but not from those dealing with the same professional tasks as those of the applicants - would select the successful candidate based on this external evaluation.

The report says that this system would improve the selection of professors because evaluation would not be based on a series of tests (or exams) assessed and voted on at the time of selection but instead on the previous activities of the candidates.

CRUE, in its report, also recommends the creation of a nationwide independent Agency of Accreditation aimed at monitoring the quality of assessments being made at different universities (see Nature $404,211 ; 2000)$. This agency would be staffed by individuals from the academic and professional worlds, both in Spain and abroad. The report says that it should make its results public, and that these should take the form of recommendations to the government.

The report's proposals have been widely welcomed in the academic community. Jordi Camí, for example, professor of pharmacology of the Universitat Pompeu Fabra in Barcelona, says that it is likely to boost competition between university researchers, as well as between universities. $\mathrm{He}$ is particularly enthusiastic about the novel system for selecting professors that the report proposes.

As far as research is concerned, the report makes a series of recommendations that are in agreement with the recently approved National Plan on Scientific 


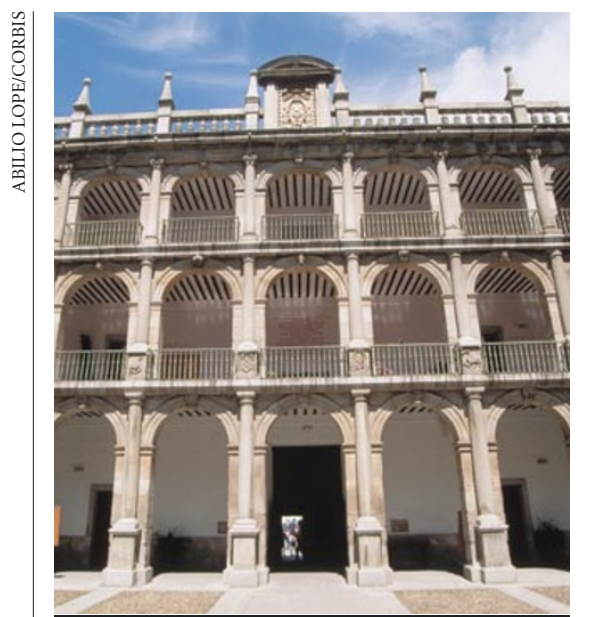

Building for the future: the new report suggests major changes for university tenure.

Research, Development and Technological Innovation (see Nature 400, 393; 1999). It proposes in particular that there should be increased support for basic research and that links between universities and industry should be boosted.

In order to increase human resources in research and development, it says that a new permanent post of research professor should be created. The occupant of such a post would be employed directly by the universities and would address the research needs of a particular department as well as carry out $\mathrm{PhD}$ teaching activities.

A revised version of the report is likely to be presented to the Parliament in September, after comments received during a period of consultation have been taken into account.

The move no doubt reflects the high dissatisfaction level expressed by researchers and professors at Spanish universities. Such concerns appear to be sorted out, at least in part, in the CRUE report.

Raul Villar, rector of the Autonomous University of Madrid, says that the report should be considered as a consultation document which is now open to comment from academics and other social groups.

He points out that, although other countries may have adopted different recruitment procedures, those that are proposed in the report seem the most appropriate for Spain, as the report respects the independence of universities from the government.

"The report has to be strongly taken into account," says Juan Carlos GuerraZunzunegui, the parliamentary spokesman on education for the ruling Popular Party. He adds that he is keen to encourage a broad debate on university recruitment.

Xavier Bosch

\section{Modified reforms end two years of deadlock at CNRS}

Paris

Amid talk last week of the imminent dismissal of France's controversial research minister, Claude Allègre (see page 430), some of his suggested reforms for the Centre National de la Recherche Scientifique (CNRS) were given provisional approval after two years of deadlock.

The reforms give the CNRS, Europe's largest public research agency, an internal administrative overhaul that has been backed by virtually everyone at CNRS. This includes the scientific unions that were bitterly opposed to Allègre when he tabled his initial reform proposals in 1998.

The most important changes approved by the agency's administrative council last week were welcomed by many scientists as bringing more flexibility and independence. These reforms include trimming the size of the scientific council - which defines the agency's scientific blueprint - and opening it to foreign members. The council will be elected internally, its members will be named, and it will choose its own president.

Another major change involves redefining the role of the president of CNRS, who will act as strategic director of the establishment and be responsible for relations with the government and universities. The director general will oversee the day-to-day running of the institution. The CNRS will also have an external evaluation committee made up of French and foreign scientists.

While incorporating some of Allègre's original suggestions, the reforms have been stripped of the most controversial elements, such as reducing the influence of the National Committee for Scientific Research. This body acts as the 'parliament' of the country's scientists, and is involved in evaluating laboratories and administering recruitment. Allègre also stepped back from handing responsibility for much of the work carried out in CNRS laboratories to the universities.

Researchers have long criticized the CNRS for being too rigid. "It's a very important loosening up of the system," says HenriEdouard Audier, a chemist at the École Polytechnique near Paris and a member of the board of a researchers' trade union, the Syndicat National des Chercheurs Scientifiques.

Audier believes the most important lesson to emerge from the two-year debate is that, once the CNRS had been given increased independence from the government, it had been able to agree on its own reforms without excessive government interference. "When there is consultation, the CNRS can modernize itself," says Audier. Heather McCabe

\section{Giant tortoises come home}

\section{London}

The one-thousandth giant tortoise (Geochelone elephantopus hoodensis) to be repatriated to its native Galapagos island of Española was released last week. This is a milestone in a breeding programme begun in 1963 to save a rare tortoise threatened by humans and human-introduced species.

Several centuries of exploitation had left a reduced and dispersed population that was not reproducing. The G. e. hoodensis project began with only 14 tortoises - all that could be found at the time. After being bred in captivity, the tortoises are reintroduced into their natural habitat (see right).

The project is led by the Charles Darwin Research Station on the Galapagos island of Santa Cruz, in conjunction with the Galapagos National Park. The research station now faces the challenge of dealing with many other threatened tortoise species. Officials says it will have succeeded when "humans are no longer needed to lead the tortoises of Española or other islands back home".

Natasha Loder

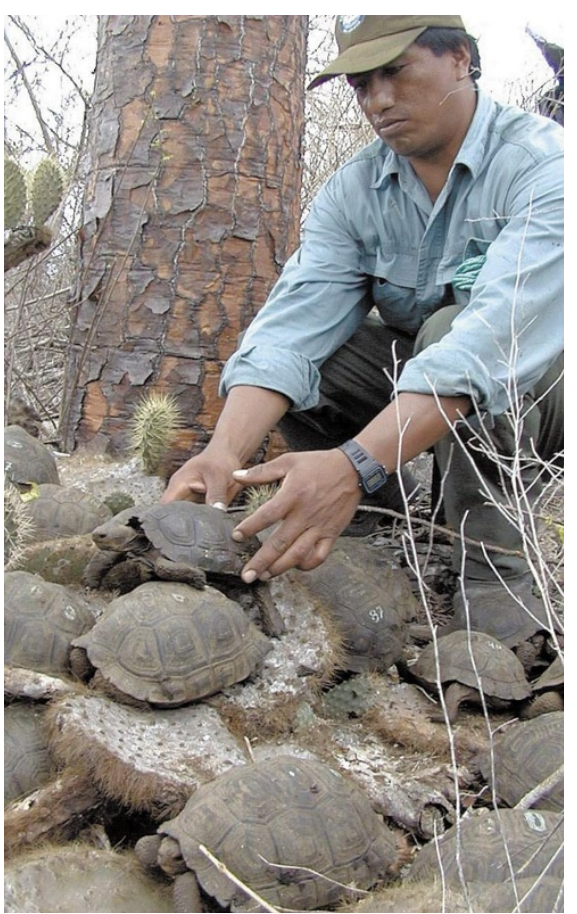

